\title{
Diabetes Treatment: Recent Developments
}

Aristidis Veves · Dimitrios Baltzis • Ioanna Eleftheriadou

To view enhanced content go to www.advancesintherapy.com

Published online: November 22, 2013

(C) The Author(s) 2013. This article is published with open access at Springerlink.com

Dear Colleague,

The prevalence of type 2 diabetes is increasing worldwide, particularly in developing countries, and follows the trend of lifestyle changes, "Western-style" diet, urbanization and increasing life expectancy. In 2011, nearly 26 million people in the United States and 366 million people globally had diabetes, while half of those were unaware of their condition. By 2030, the number of diabetic patients is estimated to almost double.

Despite the multidisciplinary approach of diabetic patient, diabetes persists in being the leading cause of cardiovascular disease, blindness, end-stage renal disease, and nontraumatic lower limb amputations, while it is the fourth or fifth leading cause of death in

A. Veves $(\bowtie) \cdot$ D. Baltzis · I. Eleftheriadou Beth Israel Deaconess Medical Center, 330 Brookline Avenue, Boston, MA 02215, USA

e-mail: aveves@bidmc.harvard.edu

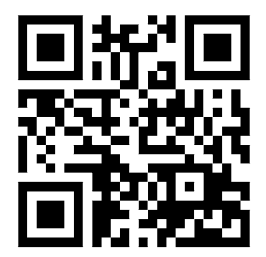

Enhanced content for Advances in Therapy articles is available on the journal web site: www.advancesintherapy.com developed countries. Optimal glycemic, lipid, and blood pressure control prevents the onset and retards the progression of diabetic complications. However, more than 50\% of patients with diabetes need additional lowering of cardiovascular risk factors. Currently available treatment approaches for macro- and microvascular complications of diabetes are mostly symptomatic without an effect on underlying causes and on the natural history of the disease. The development of new etiological treatment options remains challenging.

Pharmacologic treatment of hyperglycemia has changed dramatically in the last 10 years, with new drugs and drug classes becoming available. Several classes of pharmacological agents have been approved recently. Glucagon-like peptide-1 (GLP-1) agonists (exanatide and liraglutide), dipeptidyl peptidase-4 (DPP-4) inhibitors (sitagliptin, saxagliptin, linagliptin, and alogliptin) and selective sodium-glucose transporter-2 (SGLT-2) inhibitors (canagliflozin) are the most recently approved medications. GLP-1 agonists and DPP-4 inhibitors are placed in the second step of diabetes management algorithm as an add-on therapy to metformin. 
Nevertheless, clinical experience with SGLT-2 inhibitors is little and their place in the management algorithm remains to be defined. In clinical trials canagliflozin efficacy has been evaluated as monotherapy, as well as add-on combination therapy to metformin, to sulfonylureas and to insulin.

The main developments during the last year are related to studies about the safety of DPP-4 inhibitors and insulin. Thus, despite growing concern over the last years that treatment with DPP-4 inhibitors is associated with increased risk of pancreatitis and pancreatic cancer, two large recently published randomized controlled clinical trials demonstrated that treatment with saxagliptin and alogliptin is not associated with an increased risk of either adverse outcome [1, 2]. Both studies were cardiovascular safety studies and found that the above DPP-4 inhibitors are not associated with either reduced or increased cardiovascular risk.

Ultimately, many patients with type 2 diabetes will be treated with insulin. For the last 4 years, after the publication of 4 observational studies, there was growing concern regarding the potential link between treatment with insulin analog glargine and malignancies, especially breast cancer. Since the studies had several limitations and the results were conflicting and inconclusive, a large randomized controlled double-blind international trial was conducted. According to the published study conclusion and the new sub-analysis of the trial presented at the American Diabetes Association 2013 Scientific Session, the use of insulin analogs is not associated with an increased risk of any cancer in individuals with diabetes [3].
Even though considerable progress has been achieved over the past years, management of diabetes and its complications remains a major challenge. Until novel pharmacological agents are available for clinical practice, implementation of existing knowledge and available treatments remain the mainstay of management. After all, the best treatment is the one that gets done. The knowledge that available treatments are safe can only help the health care providers to make better plans for their patients.

\section{CONFLICT OF INTEREST}

Aristidis Veves, Dimitrios Baltzis, and Ioanna Eleftheriadou declare no conflicts of interest.

Open Access. This article is distributed under the terms of the Creative Commons Attribution Noncommercial License which permits any noncommercial use, distribution, and reproduction in any medium, provided the original author(s) and the source are credited.

\section{REFERENCES}

1. Scirica BM, Bhatt DL, Braunwald E, et al. Saxagliptin and cardiovascular outcomes in patients with type 2 diabetes mellitus. N Engl J Med. 2013;369(14): 1317-26.

2. White WB, Cannon CP, Heller SR, et al. Alogliptin after acute coronary syndrome in patients with type 2 diabetes. N Engl J Med. 2013;369(14):1327-35.

3. ORIGIN Trial Investigators, Gerstein HC, Bosch J, et al. Basal insulin and cardiovascular and other outcomes in dysglycemia. N Engl J Med. 2012;367(4): 319-28. 